\title{
Uncharted territory: Visitor books of Indian museums. The Madhya Pradesh Tribal Museum in Bhopal - a case study
}

\author{
Ina Ross*
}

\begin{abstract}
Visitor books for the general public are rather uncommon in India. As far as research is concerned, they are still mostly uncharted territory. The few existing visitor books, however, acquire a special significance: as pioneers in a nascent dialogue between visitors and institutions. This article explores their potential for providing information about the visitors to museums in India: their expectations and experiences, even their consciousness as citizens. Taking the visitor book of the Madhya Pradesh Tribal Museum in Bhopal in central India as an example, the article shows how the priorities of Indian commentators differ significantly from what researchers have found in visitor books of museums in the West - in terms of the issues addressed, of the form and style of the comments, and of the social references. This piece of research is part of a larger study examining how the historically foreign concept of the museum can be culturally adopted and made its own by an Indian public.
\end{abstract}

Key words: visitor books, visitor books India, audience research, Tribal art and culture exhibitions, museums visitor India

\section{Introduction}

Visitor books ${ }^{1}$ are not a common sight in Indian institutions. If available, they are intended more for VIPs or foreign dignitaries and serve the same purpose as the 'Golden Book' in a German city or municipality. The museum staff is instructed to request prominent visitors to sign in the book and the comments therefore tend to be formal - more along the lines of a greeting or respectful admiration than a comment, feedback or indeed criticism.

Visitor books for a general audience, which are common in western institutions, are rare in India. In research, they are still uncharted territory. After all, to write in a guest book after having visited the museum is not as yet a "part of the ritual of exhibition visiting" in India (Macdonald 2005: 125). Consequently, the few visitor books that do exist acquire a special significance: as pioneers, as it were, in what is as yet a nascent dialogue between visitors and institutions. On the one hand, they are an expression (or at least a harbinger) of growing self-confidence among visitors vis-à-vis the institution (usually part of government in Indian cultural life). On the institutional side, they are a sign of the first tentative steps being taken towards a change in mindset, a shift away from the old perception of an authoritarian and rigid institution to a new, visitor-friendly image.

In this article, I offer a starting point to understanding what might be going on in this new relationship between Indian museums and their visitors by analysing the visitor books from the Madhya Pradesh Tribal Museum (in short: Tribal Museum). It will, of course, be necessary to study a greater number of visitor books from more Indian museums to confirm and further elaborate on the conclusions of this article.

The state of Madhya Pradesh (MP) in Central India is known for its rich and diverse tribal culture. The Tribal Museum was inaugurated in the capital, Bhopal, in 2013. While the museum aims to attract an urban public, it also caters to the tribal communities themselves. The building, with its spacious surroundings, is situated in the midst of a museum complex, 
within walking distance of two other institutions, the State Museum of Madhya Pradesh and the National Museum of Mankind. ${ }^{2}$ The exhibits in the Tribal Museum portray the everyday life and spiritual world of tribal communities, in addition to their art. Relying not only on original works and pieces, the museum also has larger-than-life reconstructions and replicas that lend themselves well to its large rooms and spacious grounds. The focus of the display is not on individual exhibits but on installations and tableaux made up of a variety of objects (wall paintings, sculptures or articles of daily use).

The visitor book analysis presented here is part of a larger study that aims primarily to address the question of how the "borrowed institution" 3 of the museum in India can be culturally and socially adopted by its users and adapted to local life. The guest book is one of the sources of information that provide an insight into these processes. The article will show that the priorities set by visitor-book commentators in the Tribal Museum in Bhopal are clearly different from those set by writers in the West, the differences being apparent in the issues addressed, in the form and style of the comments, and in the social references. Another difference lies in the degree to which the guest-book authors represent visitors as a whole. Generally speaking, the entries give us a remarkable insight into the needs of museum visitors and their expectations of the institution. Guest books prove to be valuable evidence of the influences and attitudes with which a segment of the Indian public approaches a part of its cultural practice. A closer look at these sensibilities is essential if cultural management measures are to be adopted to increase acceptance of the museum as an institution in an environment as complex as India's. The article will highlight two main concerns and characteristics of the comments. Firstly, the visitors present themselves as "experts of everyday life", sharing advice in terms of how the museum should be run so that everyone feels comfortable and has a great time. Secondly, they speak pointedly as citizens, expressing strong feelings of national pride as well as a civic responsibility for the institution.

\section{Visitor book research in the Western context}

In the wake of a growing interest in visitor responses, the guest book, as an object of research, has been discovered in the last few years by museologists in the West (incl. Pekarik 1997, Livingstone et al 2001, Macdonald 2005, Morris 2011, Miglietta et al 2012, Bounia 2012, Coffee 2013, Noy 2008a, 2008b, 2015, and for exhibitions in the Soviet context of surveillance: Reid 2000, 2005). Nevertheless, according to Coffee, guest books (even in the West) are still 'under-used and under-analyzed by museums and in museum literature' (Coffee 2013: 166). A brief overview of Western insights into the visitor-book from research done so far is useful, as it provides us with a context for interpreting the guest book in Bhopal and enables us to draw comparisons. ${ }^{4}$

Even though guest books, according to Morris, are the best place for expressing strong opinions in a limited space (Morris 2011), many of the studies show that visitor comments tend to be positive and approving (Pekarik 1997, Katriel ${ }^{5}$ 1997, Miglietta et al 2012). They also relate to each other: The "well-thumbed state" of the books in the Moscow Manege exhibition hall leads Reid to conclude: '...viewers read each other's remarks before formulating their own opinion in dialogue with them" (Reid 2005: 679). The comments, although initially addressed to the institution, are thus "dialogical events in themselves" (Coffee 2013: 165). The presence of the books encourages visitors 'to formulate their own position in relation to others" (Macdonald 2005: 125).

But, above all, visitors take on the role of commentators and evaluators. They express their opinions on the exhibition theme and on the curatorial approach, on the 'object maker's motivation and intentions' (Coffee 2013: 163) or on the objects themselves (Miglietta et al 2012). ${ }^{6}$ Visitor books consequently play a 'constitutive role in visitors' engagement with the exhibition' (Reid 2005: 6). Macdonald sees the guest book itself as 'an interactive exhibit in which many visitors participate' (Macdonald 2005: 119). In addition to opinions on objects and displays, the comments analyzed by Miglietta et al, also refer to and pass judgement on the overall ambience in the museum. ${ }^{7}$ In the guest books examined by Noy, the perspective is broadened to include discussion of 'national identity and commemoration' - in other words, a political and ideological discussion of cultural memory (Noy 2015: XV). 
Much like drawing on the studies of a performance, Noy draws on tourist experiences and the way they are articulated to conclude that the guest book is also a 'stage' that is not only informative but, above all, symbolic (Noy 2008a). The visitor book offers the writer a space for expression. Minimally prestructured in the form of symbols (institution logos, emblem of the state of Israel; or, in keeping with the image of a stage, equipped with props), it leaves enough room for an independent, collective staging of aspects of a national identity, such as mourning over war casualties. An exhibit in its own right, the book is thus a continuation of the exhibition. Bounia also advocates the interpretation of the book as a stage. For her, the visitor book virtually represents the museum as a whole (Bounia 2012).

\section{Methodology}

In the age of Twitter, Facebook and Trip advisor, visitor books, as handwritten testimonials, ${ }^{8}$ are cultural and technological fossils that come with all the problems of legibility also encountered when working with manuscripts. The texts can be looked at from different angles: psychological, sociological, linguistic, anthropological, ethnological, museological - and not least, as will primarily be the case here, the culture management angle. They can be analyzed in a rather more informal, open and interpretative manner (this study will be based largely on this method), as has been done, for instance, by Sharon Macdonald ${ }^{9}$, Bonnie J. Morris ${ }^{10}$ and Chaim Noys. ${ }^{11}$ Or the texts can be subjected to computer-based, detailed categorization and tabulation - as is otherwise the norm in quantitative visitor research - which is the method used by Anna Maria Miglietta, et al. ${ }^{12}$ and Andrew J. Pekariks. ${ }^{13}$

The methodology used for the visitor book analysis will be open and interpretative. The comments are only one component of the research on museum visitors. They will be combined with visitor interviews, visitor observations, expert interviews and material analysis (website, museum advertisements, museum concept papers). As will be explained later in the text, it is advisable to exercise caution when judging these comments with reference to the extent to which they are representative of the audience as a whole. ${ }^{14}$

\section{The guest book in the Tribal Museum in Bhopal}

There are two guest books in the Tribal Museum in Bhopal. One of them is more along the lines of the 'Golden Book' described earlier in this article, with the entries (often together with an author photo) being photographed and posted on the museum's website. This book is reserved exclusively for use by VIPs and public figures from India and abroad. This is where you can find comments made by the late veteran Bollywood star Om Puri, by high court judges, highranking officials or the High Commissioner of South Africa. These comments, which are more in the style of a greeting, will not be considered in the following analysis. The focus will instead be on the book for 'general' visitors to the museum who do not enjoy any special prominence. The book is located near the ticket counter at the entrance/exit of the museum. Its position encourages visitors to reflect on their overall impression of their time at the museum, to draw a conclusion as 'an audience-contributed gesture of closure' (Katriel 1997: 71). Even though, as already mentioned, a visitor book is not a given in India's museums, the book in Bhopal is not presented in any special way. No particular effort is made to draw your attention to it and there is no specifically designated pedestal or table, as Noy describes when referring to the visitor book at Ammunition Hill National Memorial Site AHNMS in Israel (Noy 2008: 515). ${ }^{15}$ In Bhopal, the presentation is more casual. Their remarks and comments are read $^{16}$ by the museum management and some of the suggestions are also implemented. ${ }^{17}$ The assumption therefore is that the visitor book is a serious attempt on the part of the museum management to engage in dialogue.

\section{Who writes?}

The Bhopal museum visitor book that was made available to the author contains 532 entries. This was the most recent book to be completed. The first comment is dated 19 April 2014, the most recent one 6 September 2015. ${ }^{18}$ The comments in the book are written primarily in two languages, Hindi and English. There are 91 entries in Hindi, the language of MP and the dominant 
language in north India. One entry is in Marathi, the language of Maharashtra, a state in the south-west of India. In other words, Indian languages account for 17.1per cent of all entries. The remaining entries are composed in English. Rather than allow us to draw conclusions about geographical or national origins, this tells us more about the levels of education and the social status of the writers. A command of (oral and written) English is a mark of social distinction in India, the defining feature and characteristic of the educated upper middle class which has, as a rule, been educated in English and uses the language widely, both professionally and privately. This means that at least 80 per cent of the writers may belong to this social segment, which accounts for a tiny minority, a single-digit percentage of the country's total population.

None of the entries suggests that the authors themselves belong to the tribal communities, even though the museum does have its share of tribal visitors (special bus tours are organized for them). This may be because tribals, being marginalized in Indian society and often not properly educated, are not used to talking -let alone writing - about themselves, not even in an institution devoted explicitly to their culture. ${ }^{19}$

There are 375 entries by men, only 119 by women. That male voices are pre-dominant, is no surprise in India. From the urban scene, to labour market participation, to representation in the political system - the public sphere and public life in India are largely dominated by men.

11 entries could not be assigned to any gender ${ }^{20}$; one entry did not carry a name.14 are collective entries. The comment collective could be colleagues -as in the case of an entry that carries the title: 'Govt. of India m/o Finance CGA. New Delhi AAO (c) Passee IVth Batch 2013'. ${ }^{21}$ The detailed reference contains the following information: '35 Government officers (Newly Passes)'. Or the collective comments represent interests as in the entry (in Hindi) by the 'senior citizen group, government of MP employee, Bhopal'. Four male names are listed below, along with their respective designations, e.g. 'secretary', 'working member', etc. And finally, there can also be family entries where each family member is mentioned by name.

The prominence of the educated upper middle class in the guest book is also reflected in the fact that 34 individuals have preceded their names with 'doctor' as a title and two have signed as professors. Taken together, this amounts to 6.76 per cent of the total number of entries. 12 entries have been made by foreign tourists whose countries of origin are listed as France, Germany, Italy, the United Kingdom, Afghanistan, Tunisia, Estonia, Ghana and Denmark.

\section{The columns: A request to be brief}

In Western museums or cultural institutions, visitor books are often created by the institution itself and include logos, elements of corporate design (e.g. certain colours), as well as the name and address of the institution (Noy 2008). The visitor book in Bhopal, in contrast, has been bought 'off the shelf' and is therefore not designed for any particular use. It can be used as much for compiling the guest list for a marriage as it can for writing complaints in restaurants or hotels. ${ }^{22}$

The guest book has the following entry columns: Date, name, telephone number, email address and a column for comments. The pages are lined and are designed for written comments, not for drawings or playful visuals. The large majority of writers have filled in all the columns, including the two specified for contact details. Some visitors have also provided additional information, for instance about their profession, e.g. 'architect', 'Tamil writer', or 'artist'. Even though only the email address is asked for, many of the visitors add the name of their place of residence - some provide details of the bus stop (almost to make sure that the museum management will be able to find them and carry on the conversation face-to-face), some only give the name of the hometown, while the foreign visitors usually mention the country of origin. There are no completely anonymous entries, i.e. those without any name. Only four of the writers have signed just with their first names and have not provided any additional identification such as telephone number or email address.

Compared with the space available for name, email address, telephone number and even the date, the space reserved for comments is sparing and is a request to be brief. If the visitor would like to write at length, he either has to write in very small letters or has to ignore the lines dividing the columns and 'claim' his space (and some of the writers take a delight in doing this). The limited space throws up the question of just how interested the museum actually is in obtaining detailed feedback. Or whether the Golden Book tradition does not play 
a role here, too, and the focus is more on a greeting and on collecting names like trophies. Or whether the inspiration is the register placed in the guard house located at the entry to several Indian institutions in which a note is made of the visitor and their car, if they have one.

\section{The nature and style of the comments}

Guest book entries in Bhopal differ in tone from what researchers have typically found in remarks in visitor books of museums in the West. They are generally not in the nature of a dialogue (Coffee 2013, Reid 2005). None of the contributions refers to a previous entry, passes a comment on a remark already made, or takes a stand on something written in the book. They therefore differ from the contributions made in other media in the public space, i.e. social media or in the comment sections on websites. Neither is the rough tone that now dominates social media evident in the visitors' book in Bhopal. There are no examples of entries in the style of 'drunken phone calls' or 'drive-by shootings', as Morris illustrates so well (Morris 2011: 243). Similarly, there is little of 'the light and humorous air' in the comments in Bhopal, as demonstrated by Noy with reference to certain visitor books and their entries (Noy 2015: prologue). Writing comments here is sober, serious and polite, sometimes even emotional in the positive sense. The style of most of the comments tends to be more official and formal. Entries such as 'Hi my name is Lindsey. Facebook me. I love cows! Go vegetarian' (Morris 2011: 245), or 'Ridiculous garbage. Get rid of it' (Pekarik 1997: 61) would be difficult to imagine in the visitor book in Bhopal. The use of smileys to add visual or emotional emphasis is rare and there is only one entry that uses a combination of smileys and hearts to convey its message. No commentator writes over the contributions of others (even when space is at a premium). Even outwardly, the entries are shaped by politeness and respect.

Most of the entries use one or two sentences, sometimes just a couple of words to express their enthusiasm, approval and joy. Longer texts, in contrast, usually follow a defined pattern: starting with compliments and leading up to criticism or suggestions. This is illustrated by the following example, a comment entered by a female visitor (in English) who was obviously visiting the museum with her baby: 'Everything is very nice. But there is a need for improve the amenities, one feeding room and pram for babies is needed.'

The comments contain virtually no personal references or stories. Only three commentators provide biographical information. One visitor writes (in English): 'Fantastic it has taken me to my native place and childhood'; after complimenting the museum, a married couple notes (in English): 'Having worked in the Forest service I could correlate my association also.'23 Another visitor recalls (in English): '1971-75. My best years of my life in Bastar ${ }^{24}$ \& Jagdalpur ${ }^{25}$. I could visit many villages. Thanks to the museum I relived those golden years today.'

The commentators in Bhopal are therefore hardly the potential 'producers of the exhibition' who contribute to the 'large', i.e. official narrative of the exhibition with their own 'small' personal ones (Rowe et al 2002). For one, this has to do with the social position and status of the writers. They themselves are not 'tribals' and therefore do not belong to the communities whose lives are on display in the museum. That sets limits on identification. Yet, to the commentators, the guest book does not seem like an appropriate place for personal statements. Many of the remarks are in the third person, such as 'one should/must', 'there is a need', 'one little suggestion', 'advise' or as a direct request: 'please do....'. Some of the comments, even though they bear just the one name, are stylized, as though they represent larger collectives with shared interests, problems or identities. For example, two older women visitors write (one in English, the other in Hindi) on behalf of the 'senior citizen': , It would be better, if you allow the cars to come up and drop the senior citizen as it is difficult to come up.' ${ }^{26}$

In her choice of words, the second writer makes it particularly clear that she is not voicing just her individual need but is writing in the name of a group: 'I am happy while seeing this museum. On the behalf of senior citizen I only present one wish, please provide wheelchair facility it will make visit more comfortable.' Another commentator criticizes (in English) the poorly illuminated description boards; he acts as the spokesperson of 'interested visitors' who 'can't educate themselves and benefit' because the current situation is not satisfactory. 


\section{Visitors in Bhopal - Experts of everyday life}

Not only is the tone used by the commentators in Bhopal different to the tone sometimes used in western guest books, the issues they address are also different. The writers usually do not pass a general opinion on the exhibition and the exhibits. Nor do they say much about individual objects, curatorial positions or other substantive aspects. Even the controversial concept adopted by the Bhopal museum of not putting originals on display but of enlarging or replicating everything, is not commented on. Only a handful of comments focus on content. One comment (in Hindi) lists a series of local gods and regrets their absence in the museum. That the visitors are not keen to play the role of critic was also apparent when the museum management distributed feedback forms for the theatre and dance performances held on the museum's stage. The idea was abandoned, as none of the visitors filled in the forms. In contrast to the National Air and Space Museum in Washington DC (Pekarik 1997) ${ }^{27}$, for instance, the Bhopal public did not and does not seize the opportunity to record its view of artistic content and forms of display.

Nevertheless, the guest book certainly does encourage visitors to express their opinions, criticism and wishes. Yet other issues, namely aspects of management and marketing, take centre stage. The visitors do not see themselves as amateur experts in curatorial matters but as 'experts of everyday life' who know what is required for them and other visitors to feel comfortable in an institution. And they play this role with confidence and self-assurance.

A visitor makes the following comment (in English): 'Amazing building \& maintained. A small suggestion - Please BAN carrying Pan, Gutkha, Pouch, Bidi \& Cigarette inside. I have seen staff members smoking insides \& making the place untidy. ${ }^{28}$ Similarly, a visitor (in Hindi) would like to see the central government initiative, the Clean India Mission, or Swachh Bharat Abhiyan, implemented in the museum too: 'Do not allow slippers inside so that the museum remains clean and the Swachh Bharat Abhiyan will be here also successful.'

To appreciate the meaning of these remarks one first has to be clear that functional, well-maintained surroundings are by no means a given in public institutions in India (in contrast to the West). That the place is well ventilated and air conditioned, that the toilets are clean and that the canteen offers good service - all this is important in judging the quality of an institution with public traffic, yet cannot be taken for granted. In this context, visitors observe and judge the museum just as they would observe and judge a bank branch or a railway station. It is singled out as a part of the world they live in and is not seen as an institution located in a specialized sphere with its own set of rules and regulations.

This is also reflected in the manner in which social sensibilities filter into the museum's daily routine. One entry, for instance, deals with the arrogance of the political class. India is a highly hierarchical society in which the social elite and important government servants take numerous privileges for granted, an attitude that is attracting increasing criticism - in the media, in inter-party debates, and in private discussions. One of the writers in Bhopal (in English) had to witness how the general ban on flash photography in the museum obviously did not apply to a chief minister from Nagaland (a state in the north-east of India). Having established that: 'This should not be. Rules should be equal for everyone,' the commentator requests the museum management to 'Kindly reply us. We are waiting for your feedback.' $\mathrm{He}$ would like to see his perception of a culture of fairness respected in a museum too and he fails to understand the need for special rules. Just how important this is to him is expressed by his determination to take the matter further.

One writer addresses another relevant subject (in English): child labour. The Indian upper middle class, to which the visitor-book commentators belong, is clear that this is a difficult social problem. It is also aware of the serious damage this can cause to the country's international image. Having observed minors working in the museum canteen, the commentator calls on the museum management to: '... Please you must focus on child labourer in canteen in side this place ...'- and in the rest of the sentence he makes it clear that he sees a larger social problem here: ' $\&$ anywhere else.' Here, too, the museum is not seen as a special space but is taken to be a part and an example of society as a whole. 


\section{Recommendations for the management}

This is where the real significance of the guest book lies: it contains appeals to the management to take certain measures. The criticism is often pragmatic, detailed and carefully written. For example, the 'senior citizen group, government of MP employee, Bhopal' has numbered its points (in Hindi) much like a task list that can be addressed point by point:

1. Charging just 10 Rupees is too low. Make it 20 Rupie that would be good.

2. Make children up to 5 years free entrance. And from 5-12 years make it 10 Rupies.

3. Do not close this museum on national holidays such as 26 January (I.R.: Republic Day) or 15 August (I.R.: Independence Day). Because a lot of people try to visit this museum on these particular days and it was closed. They were disappointed. Give holiday to the employee of the museum on some other day so that it will remain open on National holidays.

A numbered task list can be found in several entries. On one occasion, there is a particularly vehement request to take action: having complained about the unsatisfactory state of the cafeteria, one writer ends with the imperative (in English): 'Do something!'

It is interesting to note that while the entries identify particular shortcomings, they also make constructive and concrete suggestions regarding a remedy. Thus, for instance, a visitor's plea (in Hindi) to pay attention to maintenance and upkeep is immediately supplemented by a concrete idea of how this could be done:

...One must take care of its special preference should given to the maintenance of such places. At last one more suggestion, that the soft clothes slippers should be given to the visitors so that the museum can remain clean and it will stay for longer.

One visitor even offers (in English) to help actively and personally in eliminating the problems identified by him: 'The description boards have a lot of spelling and grammatical errors. It will be very good if they are corrected. Feel free to contact for assistance in the same.' Followed by the telephone number and email address. The drift of what another visitor writes is more general but similar (in Hindi):

'This museum is very beautiful and we promise that we help in every possible way to make it more beautiful.'

After starting with a rich compliment ('Earth shaking marvel work'), one woman visitor (with an academic degree) draws up concrete suggestions (in English) of how the museum's financial situation could be improved:

Please print picture/postcards of each of the master pieces, with an explanation and huge funds can be generated. That can be utilized for the welfare of the tribal artists as well as the museum. Post cards, CD's, small booklets can generate excellent funds. (...) A variety of articles can be kept for sale (not legible) income. Most of the comments that include specific suggestions for improvement address the following thematic areas: Concern about maintenance and upkeep; unsatisfactory service in the cafeteria; cleanliness in the toilets; the lack of a water cooler $^{29}$ in the summer; the lack of a personal guide ${ }^{30}$ and inadequate marketing. Some of the entries refer to specific incidents that upset the visitor, for example (in Hindi): 'The staff member named [redacted] misbehaved with us. We were upset. Some action should be taken against him. (...) Please inform us.' In this case the visitor book is understood and used as a kind of complaint hotline to the museum management.

However, there are two issues that are most frequently addressed. Firstly, the admission fee of Rs 10 is criticized as being too low and visitors demand an increase. The writers fear that the institution may not be able to carry on in the long term, as it would not generate sufficient revenue. In this connection, some of the commentators would like to see foreign visitors charged even more than the current fee of Rs 100, which is already ten times more than what Indian 
citizens pay. One visitor even demands (in English): 'Amend the Entry ticket for foreigners not less than 100 US Dollar \& for Indian RS 100.'

Another complaint is that the charge of Rs 50 for photography is too high. This seems surprising, given that many visitors think the museum should generate higher income to remain sustainable. But opinions probably differ here about what constitutes the 'core' of a museum visit. From the perspective of the museum management, permission to use a camera is a special right that has to be acquired independently by the visitor before viewing the objects on display. This viewpoint is obviously not shared by many visitors.

If other visitor books establish a link between the visitor and the exhibition (Macdonald 2005, Reid 2005), in Bhopal it would be more a case of the visitor book including the visitor in taking responsibility for the museum project as a whole. The many suggestions for improvement are an indication that the visitors are aware of the effort involved in such an undertaking. They want to be involved, feel responsible, and, because of their daily experiences, also believe they are competent enough to make a contribution.

\section{National pride and politics}

The museum in Bhopal fills the Indian visitor with pride for the country and its culture. In the visitor book visitors share these feelings and celebrate their nation and cultural identity. In a country like India, where the collective memory of foreign colonial rule has by no means been erased, and in a country beset by myriad problems, national pride is a precious feeling. In their brief texts, the visitors allow us a glimpse of just how important it is to experience this feeling. For example, a couple writes (in English) that this experience is a jewel to be taken away and cared for:

'Excellent place. We feel very proud for this. We will carry + cherish this memory to (not legible). Thank you.'

Another visitor thanks the museum (in English) for allowing her to feel proud as a native of her state:

'Looking to this I was proud to be a resident of Madhya Pradesh. Thanks for making me feel proud.'

This regional or national pride also finds expression in comments celebrating the cultural wealth of India or of Madhya Pradesh. A visitor writes (in English): 'It was really an awesome experience to witness such an immense heritage of our state and thanks for showcasing the artwork in this magnificant way.' Or another woman writer (in Hindi): 'In Bhopal we learned about our unique Indian culture and our heritage. I think our children know nothing about this yet. Thank you to all the people who made this possible.'

Another variation of the theme is found in the comments that compare the Tribal Museum with other museums. What is interesting here is that the writers usually do not orient themselves to institutions in the area (after all, there are two museums in the immediate vicinity, including the thematically related Museum of Mankind). Some of the comments do draw a comparison with Indian museums but more to set the Tribal Museum apart. One writer states (in Hindi): '...Such kind of museums one finds generally not in India.' In another comment (in English) other museums are mentioned but more as deterrents: 'I feel horrible to see the Indian (M.P.) museums. Thanks for (...) making this museum.'

However, the primary goal is to establish the Tribal Museum on a par with other international institutions. Not 'class India' but 'world class' is the reference point. ${ }^{31}$ Almost all the comments that judge the museum on the basis of a comparison use this or a similar term. A visitor writes (in English): 'World class stuff in here.' After calling for the admission fee to be raised and criticizing the inadequate marketing, a specific comparison is made with the United States:

'....In the USA the same place would have been surrounded by (not legible)... and entry fees would have been above 25 US \$.' 
Another writer praises the interior designer of the museum:

'...It is a world class presentation. The artist Mr. Bhatty ${ }^{32}$ deserves the highest recognition for his work...'

The upper middle class that expresses itself in the guest book is familiar with international standards, thanks to a foreign education (usually in the West) or to private or professional visits, and bases its judgement on these standards. An example is this visitor who invokes his travel experience as the source of his expertise (in English):

'I have visited some of the best museums in the world. This can be at par with any world class museum in the world...'

Another comment (in English) also suggests that the writer must be well travelled: 'This is a wonderful piece of art. Not seen anywhere in the world.' (In the second part, the comment includes a list of suggestions for improvement.)

The writers are proud that what has been created in Bhopal need not fight shy of a comparison with institutions abroad. Nevertheless, 'world class' also expresses a certain insecurity: the yardstick for quality and success is still provided by an external authority, namely the European-American West. ${ }^{33}$

Only a handful of comments in the guest book (four, of which one can barely be deciphered) express a fundamentally critical view of the idea of the museum and, indeed, of how the state handles tribal culture. In view of the widespread poverty in tribal communities and their precarious situation overall, they question the priorities that are reflected in the setting up of the museum. In a way, we see a negative side of national pride here, an awareness of national failure. One critic sees a paradox between the needy situation of the 'tribals' and the expenditure incurred for the museum (in Hindi): 'If the money that you have spent on this museum had been given to a poor family that would have made a real difference.'

On the other hand, another comment (in Hindi) calls on the government to play a more active role in supporting tribal culture: 'The tribal tradition and art forms are amazing and centuries old. However the Indian society was able to recognize this only in the last 60 years. This is unfortunate. The government should take a proactive role.'

A lecturer from the University of Delhi, Education Department, thinks about what is happening with real tribal life while it is being museumized (in English):

'It is highly paradoxical that the government has so much (crores) ${ }^{34}$ of money to present the tribal life in a museum but cannot spent meaningfully $(. .$.$) to sustain$ the same life in the village. Why?? Do we want them to perish or we fear that this all will perish? Why is our education policies are gearing for a development which is heading towards the destruction of this reality!!!!'

While in the first part of her comment the author focuses on the state in the shape of the government as an opponent, and criticizes it, in the second, more emotionally imploring section, she questions the 'we', the community of citizens in which the author includes herself. She does not simply celebrate being a citizen but associates with it ideas of commitment and responsibility. Yet she is also sceptical of the possible role of the museum as an alibi. The national perspective is turned around into the critical and self-critical.

\section{'The world we have lost'}

Since the start of its economic liberalization in the 1980s, India has been undergoing dramatic and radical modernization that extends to all sections of society. This drastic change is bringing about a feeling of loss and nostalgia, not only in conservative sections of society. In his study of the Indian middle class, Varma establishes a longing for the 'simplicities of an idealized past' versus the 'unpredictability of this rapid and demanding transformation' (Varma 1998: 145).

Similar sensibilities are also expressed in the guest book in Bhopal. The tribals and how they are presented in the museum become the focal point of a nostalgic discourse. The discourse revolves around life in the village with its traditional rituals. Instilling the village with nostalgia is not a new phenomenon of the time since the economic reforms and not an exclusive reaction to this museum. Even Gandhi, in his book Hind Swaraj written in 1919, had developed 
the anti-modern vision of a rural future for India. At the time, his criticism was directed against industrialization and large national governments in the European (represented above all by the colonial power Britain) sense.

In today's India, urban elites rarely have an opportunity to experience village communities in their everyday lives. The museum therefore acts as a window through which, in comfort and safety, they can take a look at (of course artificial) traditional life. As one commentator remarks (in Hindi): 'We got a chance to see the things the tribal people use to worshipping the Gods. In our daily life we would not get the chance to experience this.' Some of these nostalgic comments express concern about future generations losing their cultural roots. One visitor writes (in English): 'This museum is beautiful and have lots of beautiful aspects and it is good for our upcoming generations to know the village life as it is lost due to industrialization...' As with Gandhi, 'industrialization' stands for the problematic modernization process as a whole.

In the nostalgic comments, the world of the tribals is repeatedly interpreted as the embodiment of an idealized Indian past. An example (in English): 'Marvellous perception translated into wonderful creation of the world we have lost long before. MP Government and his great creative minds who have brought into being this beautiful world once more.' This sentimental view of course overlooks one significant fact: in contrast to what these comments would suggest, tribal villages and communities still do exist, albeit no longer 'untouched' but modified in many ways by modernity. Even tribal art is no longer only about mythical trees and animals but also portrays aeroplanes and even Western women. ${ }^{35}$ These later developments in the subjects and the way they are addressed in tribal art are not on display in the museum and it therefore does not confront any nostalgic feelings.

\section{'It touches my heart and I pray to God'}

The many emotional comments, often summed up in a single word such as 'beautiful', 'one of its kind', 'amazing', 'excellent' or 'wow', express enthusiasm for the museum. The Hindi word 'adbhut' makes a frequent appearance and means something akin to 'amazing, wondrous, astonishing' and resonates with wonder. In the Hindi comments, in particular, emotionality verges on the religious: '...My family and me extend our blessings for their (I.R.: museum artists) bright future.' Or, in another entry: '...I pray to God that this effort will continue in such a good way.'

The emotionally charged language is often striking. For instance, a woman writes (in English): 'An awesome experience. Just fell in love with the place...' (this sentence can also be found in other places in the guest book). Another visitor notes: 'The museum is so beautiful I don't have words. My soul is completely touched...' Or: '“...This museum has been made on the pillar of love and affection....' There are lines like 'my soul is happy, my heart is touched' or 'it takes my heart' in both languages.

The visitors identify strongly with the museum here and go beyond simply using and liking it. Yet these comments can also be read as counterpoints to the concern expressed about the upkeep of the museum. In a certain way, they build the emotional foundation which underlies the specific positions taken regarding the management. Just how emotionally intense it is for the visitors to appropriate the museum becomes clear here.

Emotionality in visitor book entries, partly clothed in religious vocabulary, is not unknown in the West. Typically, one comes across them mainly at memorials and documentation centres for war and other profound and stirring historical events (Macdonald 2005, Morris 2011, Noy 2015). As described by Morris, such places are 'built to house our pain' (Morris 2011: 243); personal memory and emotion are part of the curatorial concept. Cultural and art museums, however, seem to rarely fuel such emotional statements.

\section{Conclusion}

As studies of guest books in the West have shown, the comments made here refer primarily to the display and to the content of what is on show. In the books we often encounter 'expert visitors' (Davallon et al 2000) who have developed an overview through comparisons between museums and believe this empowers and entitles them to offer profound criticism of the exhibition, its design and the curatorial approach. Particularly in the guest books in historical 
museums and memorials we also encounter visitors who acquire their expertise from their personal biographies or from their (e.g. family) ties with witnesses of the time. Both are more than just the receivers of curatorial messages; they are 'producers', 'constructors of meaning' (Rowe et al 2002: 104), or 'visitor-as-author' (Davallon et al 2000: 60) for the exhibition. Or they are homines ludentes who only want to play and romp, to draw in the pages of the book, or make provocative statements just for fun.

The visitor who appears in the guest book in Bhopal, is first and foremost a citizen - in a double sense. They are an Indian citizen in daily life in India who would like to see the museum (also in the name of their co-citizens) in good shape. They are responsible for the entries, most of which are directed at the management and are about the maintenance of standards, about practical operations and express concern about the upkeep of the institution. Secondly, in the guest book we encounter the citizen who is interested in the museum as a national project and in what it says about their country or region. While their reflections focus on concrete social problems such as VIP arrogance and child labour, they may also make more general observations, for example of the relationship between the modern and the traditional in India or about national self-awareness. The citizen reflected in the mirror of the Bhopal guest book is not an expert or critic of aesthetic and curatorial practice ${ }^{36}$ their interest and judgement focus instead on the social realities on display in the museum and in which the museum exists. The display itself and the self-expression of the individual visitor are relegated to the background.

The guest book in Bhopal therefore is not as informative for curators as it is for museum managers and culture policy-makers. For them, however, it is certainly worth taking note of. Based on a successful example, the book shows how the institution of the museum, which is often marginalized and unpopular in India, can be appropriated by the public and how it is more than capable of arousing interest, engagement and emotion. It is certainly possible to enter into a dialogue with the visitors and to win them over as active participants in the 'museum' as a social happening -only the priorities in this dialogue may be different from those studies of Western institutions have identified. The visitors can be mobilized less as co-producers of the display and more as co-translators who translate the museum as a 'borrowed institution' into the reality of everyday life, social discussion and the national discourse in India. The process of translation and appropriation can be followed in the guest book. It can also be read as advice given by the public itself on how it can identify even more strongly with the museum.

Received: 6 September 2016

Finally accepted: 20 February 2017

\section{Notes}

1 The terms 'guest book', 'comment book' and 'visitor book' are used as synonyms.

2 Indira Gandhi Rashtriya Manav Sangrahalaya

3 In his essayistic travelogue, India: A Wounded Civilization, written back in 1977, the Nobel Laureate V.S. Naipaul was already speaking about the 'borrowed institutions' that dominate the Indian political and cultural scene, Naipaul, V.S. 2003: 8.

4 Comparing the Bhopal findings to research done on visitor books in other (mostly Western) countries, one has to be aware of the variety of factors that have an impact on the style and content of comments. The type of museum may be as important in determining the nature of the remarks as the national or civilizational context. Visitors to a countryside manor house may have rather different ideas of how a proper comment should look like from visitors to a war memorial.

5 Katriel has mentioned visitor books only in a detailed footnote; they are not a focal point of her research. She places special emphasis on the polite and friendly tone of the comments, which, in language and content, are similar to the way in which a guest would talk to the host. Katriel, T. 1997: 71

6 In the study by Miglietta et al, 22.69per cent of all the comments were "linked to objects'; Miglietta, A.M. et al 2012: 93 
7 17.86per cent of all the opinions, ibid.

8 All the entries cited are original and may contain grammatical or orthographic mistakes.

$9 \quad$ Nazi Party Rally Grounds, Nuremberg, Germany

10 U.S. Holocaust Memorial Museum, Washington, USA

11 Ammunition Hill National Memorial Site, Jerusalem, Israel

12 Marine Biology Museum Pietro Parenzan, Porto Cesareo, Italy

13 Visitor feedback form at the National Air and Space Museum, Smithsonian Institution, Washington, USA.

14 Stronger conceptual categorization, as done by Miglietta et al, for instance, (on a database of 1,480 comments) would mean giving disproportionate weight to the results in the overall context of the work and is therefore not advisable.

Here the visitor book is displayed much like an exhibit - on two pillars made of black steel.

According to a museum staff member who is responsible for the visitor book.

17 Verified in the case of two specific wishes expressed with regard to the running of the museum: child labour in the canteen and acquiring prohibition signs.

18 This book had a predecessor but, despite several attempts, it could not be traced. The latest visitor book was not made available.

19 This assumption is also reinforced in the interviews with this target group.

As the forenames can be male or female.

A group of colleagues who belonged to the same year group in the Indian Ministry of Finance.

22

The successor to the book studied here is the so-called 'bahir katha', something like a diary formerly used by shop owners to keep their accounts. Today, however, it serves multiple purposes.

Most tribal communities still live in the forest, i.e. in areas covered by jungle. the exhibition ('What do you think of the exhibition?'); the objects ('Were you surprised to find this here?'); and their overall impression ('What comments do you have?'). Pekarik, A. J. 1997: 61

Pan and gutka are a kind of chewing tobacco. The bidi is a local Indian cigarette with the tobacco rolled in leaves, not in paper. Many walls and public buildings in India are discoloured with the brown-red stains of pan that has been spat out. evaporative system to keep rooms cool. 
India is not a do-it-yourself, but a do-it-for-me society. This is also true of cultural institutions. In several cultural and historical institutions, you can engage a personal guide to accompany you and to explain what you are seeing. The entries in the guest book express a desire this personal service in the museum, too; interest in an audio guide is less frequent.

31 The need to be or to live 'world class' has also been observed by Christiane Brosius in her study of consumer behaviour in the Indian middle class. She identifies different reasons for this: a symbolic topography of centre and periphery based on the assumption of the superiority of the West, followed by the influence of Indians living abroad (non-resident Indians or NRIs), and an increasingly cosmopolitan Indian middle class; Brosius, Ch. 2015: 12-13

32 Exhibit designer at the museum.

33 The insistence on being 'world class' is reminiscent of the determination with which the former East Bloc countries would claim the 'world-class' label for their domestic products. This, too, was a combination of pride and insecurity.

34 Unit in the Indian numbering system equal to ten million.

35 For an example see the works of the Gond artist Bhajju Shyam in The London Jungle Book. Inspired by a trip to England, he portrays the inhabitants of the metropolis as many-armed goddesses capable of executing several tasks simultaneously.

36 This is also endorsed by the visitor interviews. Some of the interviewees themselves indicated (particularly when being critical) that they were not experts of art or culture.

\section{References}

Bounia, A, (2012) 'The Visitor book. Visibility, Performance and Representation', in: Bose, F.v. et al (ed.) Museum X. Zur Neuvermessung eines mehrdimensionalen Raumes, 129-137, Berlin: Panama.

Brosius, Ch. (2015) India's Middle Class. New Forms of Urban Leisure, Consumption and Prosperity, London, New York, New Delhi: Routledge.

Coffee, K. (2013) 'Visitor Comments as Dialogue', Curator, 56 (2), 163-167.

Davallon, J. Gottesdiener, H., Poli, M.S. (2000) 'The "expert visitor" concept', Museum International, 52 (4), 60-64.

Gandhi, M.K. (2009) Hind Swaraj and other writings, Cambridge et. al: Cambridge University Press.

Katriel, T. (1997) Performing the Past. A Study of Israeli Settlement Museum, Mahwah, New Jersey: Lawrence Erlbaum Associates.

Livingstone, P., Pedretti, E., Soren, B.J. (2001) 'Visitor comments and the social-cultural context of science: Public perceptions and the exhibition A Question of Truth', Museum Management and Curatorship, 19 (4), 355-369.

Macdonald, S. (2005) 'Accessing audiences: visiting visitor books', Museum and society, 3 (3), 119-136.

Miglietta, A.M., Boero, F., Belmonte, G. (2012) 'Museum management and visitors book: there might be a link?', Museologia Scientifica, 6 (1-2), 91-98. 
Morris, B.J. (2011): 'The Frightening Invitation of a Guestbook', Curator, 54 (3), 243-252.

National Council for Applied Economic Research (2005) The Great Indian Middle Class: A survey of 2004, in: The Billionaire Club, 11, New Delhi.

Noy, Ch. (2015) Thank You for Dying for Our Country: Commemorative Texts and Performances in Jerusalem, Oxford: Oxford University Press.

(2008a) 'Pages as stages: A Performance Approach to Visitor Books', Annals of Tourism Research, 35, (2), 509-528.

(2008b) 'Writing Ideology: Hybrid Symbols in a Commemorative Visitor Book in Israel', Journal of Linguistic Anthropology, 18, (1), 62-81.

Pekarik, A.J. (1997) 'Understanding Visitor Comments: The Case of Flight Time Barbie', Curator, 40 (1), 56-68

Reid, S.E. (2000) 'The Exhibition Art of Socialist Countries, Moscow 1958-9, and the Contemporary Style of Painting', in Reid, S.E. and Crowley, D. (ed.) Style and Socialism. Modernity and Material Culture in Post-War Eastern Europe, 101-132, Oxford: Berg.

(2005) 'In the Name of the People: The Manège Affair Revisited', Kritika: Explorations in Russian and Eurasian History, 6 (4), 673-716.

Rowe, S.M., Wertsch, J.V., Kosyaeva, T.Y. (2002) 'Linking Little Narratives to Big Ones: Narrative and Public Memory in History Museums,' Culture \& Psychology, 8 (1), 96112.

Shyam, B. with Wolf, G., Rao, S. (2004) The London Jungle Book, Chennai: Tara Books.

Varma, P.K. (1998) The Great Indian Middle Class, Gurgaon: Penguin Books.

*Ina Ross is lecturer for cultural management at the Jamia Millia Islamia University, Faculty of Fine Arts and the National School of Drama, New Delhi, India. Her PhD research is on two museums in India. Her books and articles include Wie überlebe ich als Künstler? - How to survive as an artist?' (Transcript, 2013), 'Works in Progress - How museums in Europe redefined themselves to stay financially viable and artistically relevant' (Indian Quarterly, Vol. III, 1, 2014), 'Help from the Enemy? - What Arts Management can do for the artist' (ArtIndia, Vol. XIX, 3, 2015), 'Arts Management the Indian Way' (International Journal of Arts Management, HEC, Vol. 19, 2, 2017), 'The Mobile Theatre Movement in India: a Success Story in Assam' (New Theatre Quarterly, Vol. 33, 1, 2017)

Ina Ross,

K22 Hauz Khas Enclave, $2^{\text {nd }}$ floor,

11001 New Delhi,

India

Mobile: +91 8527020158 ,

Landline +91 1141068799

goegel@gmx.de 